\title{
Diet and toenail arsenic concentrations in a New Hampshire population with arsenic-containing water
}

\author{
Kathryn L Cottingham ${ }^{1 *}$, Roxanne Karimi ${ }^{1,2}$, Joann F Gruber ${ }^{1,3}$, M Scot Zens ${ }^{4}$, Vicki Sayarath ${ }^{4}$, Carol L Folt ${ }^{1}$, \\ Tracy Punshon 1 , J Steven Morris ${ }^{4}$ and Margaret R Karagas ${ }^{4}$
}

\begin{abstract}
Background: Limited data exist on the contribution of dietary sources of arsenic to an individual's total exposure, particularly in populations with exposure via drinking water. Here, the association between diet and toenail arsenic concentrations (a long-term biomarker of exposure) was evaluated for individuals with measured household tap water arsenic. Foods known to be high in arsenic, including rice and seafood, were of particular interest.

Methods: Associations between toenail arsenic and consumption of 120 individual diet items were quantified using general linear models that also accounted for household tap water arsenic and potentially confounding factors (e.g., age, caloric intake, sex, smoking) $(n=852)$. As part of the analysis, we assessed whether associations between log-transformed toenail arsenic and each diet item differed between subjects with household drinking water arsenic concentrations $<1 \mu \mathrm{g} / \mathrm{L}$ versus $\geq 1 \mu \mathrm{g} / \mathrm{L}$.

Results: As expected, toenail arsenic concentrations increased with household water arsenic concentrations. Among the foods known to be high in arsenic, no clear relationship between toenail arsenic and rice consumption was detected, but there was a positive association with consumption of dark meat fish, a category that includes tuna steaks, mackerel, salmon, sardines, bluefish, and swordfish. Positive associations between toenail arsenic and consumption of white wine, beer, and Brussels sprouts were also observed; these and most other associations were not modified by exposure via water. However, consumption of two foods cooked in water, beans/lentils and cooked oatmeal, was more strongly related to toenail arsenic among those with arsenic-containing drinking water $(\geq 1 \mu \mathrm{g} / \mathrm{L})$.
\end{abstract}

Conclusions: This study suggests that diet can be an important contributor to total arsenic exposure in U.S. populations regardless of arsenic concentrations in drinking water. Thus, dietary exposure to arsenic in the US warrants consideration as a potential health risk.

Keywords: Biomarkers, Drinking water, Population-based study, Food borne exposure, Rice, Fish

\section{Background}

Exposure to arsenic has been linked to a variety of adverse human health effects, including skin lesions; skin, lung, and bladder cancer; vascular diseases; low birth weight; and potentially diabetes mellitus and increased susceptibility to infection [1-3]. Although human exposure to the more toxic, inorganic forms of arsenic is thought to occur primarily through drinking

\footnotetext{
* Correspondence: Kathryn.Cottingham@dartmouth.edu

'Department of Biological Sciences, Dartmouth College, Hanover, NH, USA Full list of author information is available at the end of the article
}

water $[3,4]$, elevated concentrations of arsenic in certain foods may pose an additional risk to consumers (e.g., [2]). Foods with particularly high total arsenic concentrations include fish and seafood [5-9]; cereals and cereal products, particularly rice and rice-based products [5-7,10,11]; and bran and germ [2]. Using diet data and physiological models to estimate total arsenic exposure, Xue et al. [12] found that fruits and fruit juices, vegetables, and beer and wine also can be important sources of dietary arsenic; more recent studies document high arsenic concentrations in cruciferous vegetables in particular [13]. Importantly,

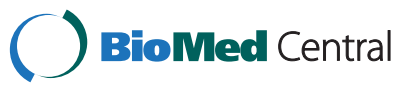


the form of arsenic differs among these different types of food: the arsenic in seafood is primarily in putatively less toxic, organic forms such as arsenobetaine, arsenolipids, and arsenosugars [9,14], while the arsenic in most other items includes both inorganic and organic forms of arsenic that have been associated with toxicity [2].

Estimates of arsenic intake based on dietary patterns and arsenic concentrations in individual food items suggest that food can be a significant source of arsenic in Western diets. For example, a recent, comprehensive report by the European Food Safety Authority (EFSA) concluded that some Europeans, especially children, may be consuming appreciable levels of arsenic through food [2]. Moreover, Xue et al. [12] estimated that the general U.S. population may be at greater risk of exposure to arsenic via food than drinking water, supporting similar conclusions by previous researchers [7,15-17]. Pregnant women, infants, children, the elderly, and those with compromised immune function could be particularly vulnerable to the health effects of dietary arsenic exposure $[1,12,18]$.

Despite these advances, neither the EFSA report [2] nor previous research (e.g., [6]) has specifically evaluated exposure via diet after accounting for exposure to arsenic via the household water supply used for drinking and cooking. Therefore, as part of ongoing studies of arsenic and cancer risk, we evaluated the relationships between long-term diet, as reported by subjects using a validated food-frequency questionnaire, and total arsenic concentrations in toenail clippings in a population with varying exposure to arsenic via household water. Toenail clippings provide a biomarker of exposure over the past 2-18 months [6,19-25]: ingested inorganic arsenic circulating through the body binds irreversibly to the sulfhydryl groups in keratin at the base of the growing nail $[22,26]$, which then grows out to be clipped some months later. Previous research indicates that arsenic in toenail clippings is positively correlated with arsenic concentration in the household water at water arsenic concentrations $\geq 1 \mu \mathrm{g} / \mathrm{L}[19,26-28]$ but is only weakly associated when concentrations are $<1 \mu \mathrm{g} / \mathrm{L}$ [19]. One plausible explanation for the latter is that dietary exposure explains more of the variability in toenail arsenic in individuals with little exposure via drinking water. Here, we evaluate whether associations between overall body burden (as indicated by toenail arsenic concentration) and potential dietary exposure from individual food items differ with exposure via drinking water.

\section{Methods}

\section{Study population}

We analyzed existing data from population-based casecontrol studies of bladder and skin cancer conducted among 25 to 74 year old residents of New Hampshire
[29-33]. Groundwater arsenic concentrations for this population vary from $<0.0003$ to $180 \mu \mathrm{g} / \mathrm{L}$ [34-36], creating a natural gradient of exposure to inorganic arsenic via drinking water. The Committee for the Protection of $\mathrm{Hu}$ man Subjects (CPHS) of Dartmouth College approved study materials and protocols (current CPHS \#10107 \& \#11697) and participants provided informed consent according to the approved protocol.

\section{Data collection}

In this study, we evaluated the association between arsenic in toenail clippings, household water arsenic, and average daily consumption of 120 different diet items for which data were available. Study participants provided toenail clippings and a household tap water sample for analysis of total arsenic concentration using previously established protocols [19,37]; most of the arsenic in both of these matrices is likely to be in the inorganic form (see e.g., [38] and [22], respectively). Toenail clippings (mass $0.04 \pm 0.01 \mathrm{~g}$, mean \pm 1 standard deviation [SD]) were analyzed at the University of Missouri Research Reactor Center using standardcomparator instrumental neutron activation analysis (NAA). Nails were washed carefully to remove external contamination, freeze-dried, and then stored in sealed vials until testing [19,37]. Samples, certified reference material, and a keratin quality control sample were irradiated for $60 \mathrm{~min}$ at a thermal neutron flux of $8 \times$ $10^{13}$ neutrons $\mathrm{cm}^{-2} \mathrm{~s}^{-1}$, then live-counted for 2 hours at a sample-to-detector distance of $\sim 10 \mathrm{~cm}$ using a high resolution gamma-ray spectrometer after a decay period of $\sim 24$ hours. Arsenic was calculated from the $559-\mathrm{keV}$ gamma ray from the decay of As-76, relative to known standards and after correction for physical decay. Quality control samples were within $1 \mathrm{SD}$ of the expected value [19].

Drinking water samples were analyzed in the Dartmouth Trace Element Analysis Core using a Finnigan MAT GmbH ELEMENT high resolution inductively coupled mass spectrometer equipped with an MY hydride generator (Finnigan MAT GmbH, Bremen, Germany) [19]. Samples were acidified to $\mathrm{pH} 1$ with ultrapure nitric acid upon arrival at the laboratory, then spiked with Suprapur $\mathrm{H}_{2} \mathrm{O}_{2}$ (Merck KGaA, Darmstadt, Germany) to $0.01 \%$ at least 24 hours prior to analysis. During analysis, hydride generation was used to separate arsenic from $\mathrm{ArCl}+$ species, increasing the ability to detect arsenic at concentrations $<5 \mu \mathrm{g} / \mathrm{L}$ [19].

Participants also completed a written, validated, semiquantitative food frequency questionnaire (FFQ) [39,40] to quantify diet over the previous year. An annual FFQ should provide a good match to the time scale over which the toenail clippings provide an integrated measure of exposure [6,37]. The FFQ asked about the consumption of 
specific portion sizes of 120 different items from seven broad categories (dairy, fruits, vegetables, eggs and meat, breads, beverages, and baked goods) over the previous 12-month period; we analyzed associations between toenail arsenic and each of these diet items. We converted all responses to servings per day using the midpoint of each interval and assuming that a month has 30 days (Additional file 1: Table S1). When participants skipped a question, we set the frequency of consumption to missing. As in MacIntosh et al. [6], we focused on whole foods; the associations between toenail arsenic concentrations and micronutrient and vitamin consumption, both with and without supplements, were analyzed separately [41].

In addition, participants were interviewed, usually in their home, to obtain information on sociodemographic and lifestyle factors (e.g., smoking history, drinking water source, [33]) that may have affected the association between toenail arsenic concentration, drinking water arsenic concentration, and individual diet items.

\section{Statistical analyses}

Prior to analysis, we normalized data on toenail arsenic concentrations using natural-log (ln) transformation. Analyses reported here exclude the 70 subjects who did not report using their household water for drinking and cooking as well as subjects who did not meet the caloric thresholds suggested by Willett [42]: 18 men below 800 calories and 13 above 4000 calories, and three women below 500 calories and four above 3500 calories. We also excluded from the analysis one individual with an extremely high toenail arsenic concentration $(7.6 \mu \mathrm{g} / \mathrm{g})$, which was $420 \%$ higher than the next highest concentration [41]. This left us with a sample size of 852 subjects, down from 934 .

In all analyses, we accounted for the previously observed non-linear association between toenail arsenic concentrations and household water arsenic concentration [19] by including natural-log transformed household water arsenic, an indicator variable [43] for whether subjects had concentrations of arsenic in household water $<1 \mu \mathrm{g} / \mathrm{L}$ or $\geq 1 \mu \mathrm{g} / \mathrm{L}$, and their interaction in a general linear model (GLM, SAS version 9.2).

We then evaluated associations with the self-reported, estimated daily rate of consumption of each of the 120 diet items in the FFQ. In the first stage of the analysis, we determined whether the association between watercorrected toenail arsenic concentration and each diet item differed between the two household water arsenic groups $(<1 \mu \mathrm{g} / \mathrm{L}$ vs. $\geq 1 \mu \mathrm{g} / \mathrm{L})$ using an interaction between the consumption rate of the diet item and the indicator variable for household water arsenic. If there was no statistically significant $(\alpha=0.05)$ interaction between the diet item and the water exposure group, we concluded that the association between water-corrected toenail arsenic and the diet item was not affected by water exposure, and fit a GLM to the full dataset in the second stage of analysis (Model 1). However, if there was a statistically significant interaction between the diet item and the water exposure group, we concluded that the association between water-corrected toenail arsenic and the diet item differed between the two water exposure groups and so conducted analyses separately for the two groups (Models $2 \mathrm{a}$ and $2 \mathrm{~b}$ ). The slope coefficients $(\hat{\beta})$ for each dietary item have the units natural-log transformed (toenail arsenic concentrations, $\mu \mathrm{g} / \mathrm{g}) \bullet(\text { servings } / \mathrm{d})^{-1}$.

For those diet items for which the slope coefficient was statistically significant for the appropriate model ( 1 or $2 \mathrm{a} / 2 \mathrm{~b}$ ), we evaluated robustness to extreme values in the predictors by looking at unadjusted scatterplots, then recalculating regression coefficients after systematically deleting visually apparent outliers. Seven diet items were no longer significant after removal of such values and were not considered further.

Although associations between toenail arsenic and demographic characteristics such as age have previously been described [19], the mechanisms behind these associations have not been elucidated. For example, we do not know whether age directly affects toenail arsenic, or whether age influences diet, which in turn influences exposure as indicated by toenail concentrations. We therefore reported "crude" unadjusted associations between water-corrected toenail arsenic and each diet item, as well as analyses after adjustment for covariates that were deemed important from previous literature $[19,44,45]$, biological plausibility, and univariate associations [41]. We adjusted for four categorical variables (sex, smoking status [never/ever], season of toenail collection, case-control status [control, bladder cancer, basal cell carcinoma, squamous cell carcinoma]) and three continuous variables (age, daily intake of water from the household water source [ounces $\bullet \mathrm{d}^{-1}$ ], and total energy intake $\left.\left[\mathrm{kcal} \bullet \mathrm{d}^{-1}\right]\right)$.

To help interpret regression coefficients from these adjusted models, we determined the percent change in predicted (back-transformed) toenail arsenic concentrations between $5^{\text {th }}$ percentile and $95^{\text {th }}$ percentile consumers for each food, using an approach similar to that described in Gruber et al. [41]. Predictions were made for non-smoking, control subjects whose toenails were collected during the most common season (fall), separately for males and females at the mean age, caloric consumption, and water consumption for their sex. For Model 1 foods (those for which associations were consistent across household water arsenic concentrations), we used the overall median household water concentration. For Model 2 foods (those for which associations differed 
between water arsenic exposure groups), we used the median household water concentration for the appropriate exposure group.

We accounted for multiple testing across the individual foods using the false discovery rate (FDR) procedure implemented in the R package qvalue [46]. Specifically, we calculated the Q-value, the minimum FDR at which a test may be called statistically significant [47], from the combined list of P-values for the association with each of the 120 foods, as generated by the appropriate model $(1,2 \mathrm{a}$ or $2 \mathrm{~b})$. We considered variables with a Q-value $>0.1$ as less likely due to multiple testing.

\section{Results}

The 852 individuals in our study had a median arsenic concentration in the household tap water of $0.30 \mu \mathrm{g} / \mathrm{L}$ and a median toenail arsenic concentration of $0.085 \mu \mathrm{g} / \mathrm{g}$. Mean arsenic concentrations in toenails were lower for those with household water arsenic concentrations $<1 \mu \mathrm{g} / \mathrm{L}$ than in the group with household water arsenic $\geq 1 \mu \mathrm{g} / \mathrm{L}$ (Table 1). Fifty-two individuals had household water arsenic concentrations at or above the EPA drinking water standard of $10 \mu \mathrm{g} / \mathrm{L}$.
Individuals with $<1 \mu \mathrm{g} / \mathrm{L}$ vs. $\geq 1 \mu \mathrm{g} / \mathrm{L}$ water arsenic were similar with respect to gender, smoking status, case status, and the season of toenail collection (Table 1). Further, there was comparability between groups in age, energy intake, and amount of water consumed from the household source each day (Table 1).

In interpreting the results of our general linear models, we focused on the foods known to be high in arsenic (e.g., rice, seafood [2]) and those foods that were statistically significant after correction for multiple testing (Q-values $\leq 0.1$ ), based on the models that included potential confounders. Although the statistical significance of some relationships depended on whether we used crude or adjusted models to evaluate associations between water-corrected toenail arsenic and diet, the direction of effects (i.e., whether associations were positive or negative) was robust to the inclusion of potential confounding variables.

For 116 of the 120 foods investigated, the association between water-corrected $\ln$-transformed toenail arsenic and diet did not differ by whether arsenic was present in the drinking water supply at concentrations $\geq 1 \mu \mathrm{g} / \mathrm{L}$ (i.e., the interaction term between the indicator variable and the diet item was not statistically significant). We

Table 1 Summary statistics for the study population

\begin{tabular}{|c|c|c|c|}
\hline Variable & $\begin{array}{c}\text { Total } \\
\text { population }\end{array}$ & $\begin{array}{l}\text { Water arsenic } \\
<1 \mu \mathrm{g} / \mathrm{L}\end{array}$ & $\begin{array}{c}\text { Water arsenic } \\
\geq 1 \mu \mathrm{g} / \mathrm{L}\end{array}$ \\
\hline Drinking water arsenic $(\mu \mathrm{g} / \mathrm{L})$ & $2.72(0.35)$ & $0.27(0.01)$ & $10.86(1.36)$ \\
\hline Toenail arsenic $(\mu \mathrm{g} / \mathrm{g})$ & $0.12(0.005)$ & $0.10(0.004)$ & $0.19(0.02)$ \\
\hline Age (years) & $61.1(0.3)$ & $61.2(0.4)$ & $60.7(0.7)$ \\
\hline Intake from household tap water (\# 8 oz. glasses/d) & $5.0(0.1)$ & $5.1(0.1)$ & $5.0(0.2)$ \\
\hline Energy intake (kcal/d) & $1920(22)$ & $1912(25)$ & $1944(42)$ \\
\hline \multicolumn{4}{|l|}{ Sex } \\
\hline Female & $330[61]$ & 254 [39] & 76 [39] \\
\hline Male & $522[39]$ & $401[61]$ & $120[61]$ \\
\hline \multicolumn{4}{|l|}{ Smoking Status } \\
\hline Never Smoked & $275[32]$ & 208 [32] & $67[34]$ \\
\hline Has Smoked & $577[68]$ & $447[68]$ & $130[66]$ \\
\hline \multicolumn{4}{|l|}{ Season } \\
\hline Winter & $168[20]$ & $127[19]$ & $41[21]$ \\
\hline Spring & $171[20]$ & $137[21]$ & $34[17]$ \\
\hline Summer & 246 [29] & $175[27]$ & $71[36]$ \\
\hline Fall & $267[31]$ & 216 [33] & $51[26]$ \\
\hline \multicolumn{4}{|l|}{ Case-control Status } \\
\hline Control & $211[25]$ & $167[25]$ & $44[22]$ \\
\hline Bladder Cancer & 248 [29] & $168[28]$ & $62[31]$ \\
\hline Basal Cell Skin Cancer & 198 [23] & $150[23]$ & $48[24]$ \\
\hline Squamous Cell Skin Cancer & $195[23]$ & $152[23]$ & $43[22]$ \\
\hline
\end{tabular}

Legend: Summary statistics are provided first for the total study population $(n=852)$, and then for the two household drinking water exposure groups: $<1 \mu \mathrm{g} / \mathrm{L}$ $(\mathrm{n}=655)$ and $\geq 1 \mu \mathrm{g} / \mathrm{L}(\mathrm{n}=197)$. Continuous variables are given as mean (SE) and categorical variables as $\mathrm{N}$ [\%]. 
found a positive association with dark meat fish, a category that includes tuna steaks, mackerel, salmon, sardines, bluefish, and swordfish and which accounted for about $1.5 \%$ of the variation in ln-transformed toenail arsenic in our adjusted model. Based on this model, toenail arsenic is predicted to be $7.4 \%$ higher among both males and females eating these fish once weekly $\left(95^{\text {th }}\right.$ percentile consumers) as compared to less than once per month $\left(5^{\text {th }}\right.$ percentile consumers, Table 2$)$. In contrast, we did not detect a clear relationship between toenail arsenic and rice consumption (adjusted model $\hat{\beta}$ for brown rice $=0.23 \pm 0.22(1 \mathrm{SE}), P=0.29 ; \hat{\beta}$ for white rice $=$ $0.065 \pm 0.15, P=0.67)$, although toenail arsenic was positively associated with two other types of grains: bran and a miscellaneous category that included bulgur, kasha, couscous, and other grains (Table 2).

Of all the diet items evaluated, only beer, white wine, and Brussels spouts were statistically significant after correction for multiple testing (Table 2). Alcoholic beverages - beer and white wine, and to a lesser extent red wine - were positively associated with toenail arsenic; partial $\mathrm{R}^{2}$ for these effects ranged from $1.1-2.4 \%$ in the adjusted models. Associations with alcohol consumption differed by sex. In men, predicted toenail arsenic concentrations are $>30 \%$ higher in those consuming 2.5 beers/day ( $95^{\text {th }}$ percentile consumers) as compared to non-consumers $\left(5^{\text {th }}\right.$ percentile consumers). In women, predicted toenail arsenic is $>20 \%$ higher for those drinking 5-6 glasses of white wine per week $\left(95^{\text {th }}\right.$ percentile consumers) compared to those who did not drink this beverage ( $5^{\text {th }}$ percentile consumers). Increased consumption of Brussels sprouts was also positively related to toenail arsenic: the models predict a $10 \%$ increase in toenail arsenic when consumption increases from never eating Brussels sprouts ( $5^{\text {th }}$ percentile consumers) to eating them once per week ( $95^{\text {th }}$ percentile consumers) (Table 2 ).

Other associations between diet items and toenail arsenic were not statistically significant after correction for multiple testing (Table 2). For example, we detected positive associations with tofu and other soy products, cantaloupe, raw carrots, celery, eggplant or zucchini, and red chili sauce, and inverse associations with consumption

Table 2 Diet items that were associated with toenail arsenic across the whole population

\begin{tabular}{|c|c|c|c|c|c|c|c|c|c|}
\hline \multirow[b]{3}{*}{ Category } & \multirow[b]{3}{*}{ Item } & \multicolumn{3}{|c|}{ Crude models $^{1}$} & \multicolumn{5}{|c|}{ Adjusted models ${ }^{2}$} \\
\hline & & \multirow[b]{2}{*}{$\hat{\beta} \pm \mathrm{SE}^{4}$} & \multirow[b]{2}{*}{$P$} & \multirow[b]{2}{*}{ partial $R^{2}$} & \multirow[b]{2}{*}{$\hat{\beta} \pm S E$} & \multirow[b]{2}{*}{$P$} & \multirow[b]{2}{*}{ partial $R^{2}$} & \multicolumn{2}{|c|}{$\begin{array}{c}\% \text { change from } 5^{\text {th }} \\
\text { to } 95^{\text {th }} \text { percentile } \\
\text { consumers }^{3}\end{array}$} \\
\hline & & & & & & & & Males & Females \\
\hline \multirow[t]{3}{*}{ Meats } & $\begin{array}{l}\text { Dark meat fish (tuna steak, mackerel, salmon, } \\
\text { sardines, bluefish, swordfish, 3-5 oz) }\end{array}$ & $0.50 \pm 0.22$ & 0.025 & $0.8 \%$ & $0.62 \pm 0.22$ & 0.004 & $1.5 \%$ & 7.4 & 7.4 \\
\hline & Beef, calf, or pork liver (3-4 oz.) & $-1.21 \pm 0.52$ & 0.019 & $0.9 \%$ & $-0.89 \pm 0.50$ & 0.073 & $1.1 \%$ & -5.8 & -5.8 \\
\hline & Hamburger (1 patty) & $-0.32 \pm 0.15$ & 0.034 & $-0.1 \%$ & $-0.32 \pm 0.15$ & 0.038 & $-0.3 \%$ & -12.6 & -12.6 \\
\hline Dairy & Eggs (1) & $-0.12 \pm 0.05$ & 0.036 & $0.4 \%$ & $-0.10 \pm 0.05$ & 0.060 & $0.3 \%$ & -7.7 & -7.7 \\
\hline \multirow[t]{3}{*}{ Grains } & Bran, added to food (1 Tbsp) & $0.14 \pm 0.08$ & 0.094 & $0.4 \%$ & $0.15 \pm 0.08$ & 0.048 & $1.0 \%$ & 0.9 & 6.0 \\
\hline & Other grains (bulgur, kasha, couscous, etc.: 1 cup) & $1.26 \pm 0.46$ & 0.006 & $1.9 \%$ & $0.80 \pm 0.45$ & 0.074 & $2.4 \%$ & 5.5 & 12.1 \\
\hline & Cold breakfast cereal (1 cup) & $-0.12 \pm 0.05$ & 0.014 & $1.1 \%$ & $-0.10 \pm 0.05$ & 0.039 & $1.2 \%$ & -11.6 & -11.6 \\
\hline Fruits & Cantaloupe (1/4 melon) & $0.22 \pm 0.12$ & 0.079 & $0.7 \%$ & $0.25 \pm 0.12$ & 0.039 & $1.0 \%$ & 9.7 & 9.7 \\
\hline \multirow[t]{6}{*}{ Vegetables } & Brussels sprouts ( $1 / 2$ cup) & $0.69 \pm 0.27$ & 0.010 & $0.3 \%$ & $0.89 \pm 0.26$ & 0.001 & $1.0 \%$ & 10.4 & 10.4 \\
\hline & Raw carrots ( $1 / 2$ carrot or $2-4$ sticks) & $0.18 \pm 0.08$ & 0.025 & $0.4 \%$ & $0.15 \pm 0.08$ & 0.048 & $0.7 \%$ & 7.9 & 14.9 \\
\hline & Celery (4" stick) & $0.25 \pm 0.10$ & 0.010 & $0.3 \%$ & $0.29 \pm 0.09$ & 0.002 & $0.8 \%$ & 11.3 & 21.8 \\
\hline & Eggplant or zucchini (1/2 cup) & $0.44 \pm 0.18$ & 0.017 & $0.8 \%$ & $0.37 \pm 0.18$ & 0.047 & $1.2 \%$ & 6.5 & 20.8 \\
\hline & Tofu or soybeans (3-4 oz.) & $0.58 \pm 0.26$ & 0.025 & $0.3 \%$ & $0.46 \pm 0.25$ & 0.063 & $0.7 \%$ & 3.1 & 6.8 \\
\hline & Salsa/red chili sauce (1 Tbsp) & $0.53 \pm 0.18$ & 0.003 & $0.6 \%$ & $0.33 \pm 0.17$ & 0.057 & $0.9 \%$ & 4.8 & 4.8 \\
\hline \multirow[t]{3}{*}{ Beverages } & Beer, regular (1 glass, bottle, or can) & $0.11 \pm 0.03$ & 0.001 & $0.8 \%$ & $0.11 \pm 0.03$ & 0.001 & $1.1 \%$ & 32.0 & 4.9 \\
\hline & Red wine (5 oz glass) & $0.12 \pm 0.05$ & 0.012 & $0.5 \%$ & $0.14 \pm 0.05$ & 0.003 & $1.3 \%$ & 12.9 & 5.3 \\
\hline & White wine (5 oz glass) & $0.27 \pm 0.06$ & 0.000 & $1.9 \%$ & $0.27 \pm 0.06$ & 0.000 & $2.4 \%$ & 12.1 & 23.3 \\
\hline
\end{tabular}

Legend: Model results for the diet items with statistically significant associations with In-transformed toenail arsenic, adjusted for tap water arsenic. Sample sizes ranged from $n=807-843$. Bolding indicates a $\mathrm{Q}$-value $<0.1$.

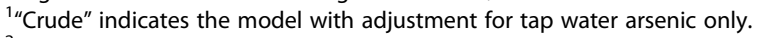

2"Adjusted" indicates the model with adjustment for tap water arsenic, age, sex, caloric intake, daily water consumption, smoking status, case-control status, and season of toenail collection.

${ }^{3}$ These columns summarize the percent change in predicted toenail arsenic concentration from $5^{\text {th }}$ to $95^{\text {th }}$ percentile consumers for males and for females; gender is included since males and females consumed some diet items (e.g., beer, wine) differently.

${ }^{4}$ Units for the estimated coefficients are natural-log transformed (toenail arsenic concentration, $\mu \mathrm{g} / \mathrm{g}$ ) • (servings/d) ${ }^{-1}$. 
of cold breakfast cereals; eggs; beef, calf, or pork liver; and hamburger (Table 2).

The associations for four foods differed according to household tap water arsenic concentration (Table 3). For cooked oatmeal/oat bran and beans or lentils, the association was stronger among those with $\geq 1 \mu \mathrm{g} / \mathrm{L}$ water arsenic. For hot dogs and liquor, the direction of the association changed for those with $<1 \mu \mathrm{g} / \mathrm{L}$ vs. $\geq 1 \mu \mathrm{g} / \mathrm{L}$ water arsenic (Table 3). None of these associations remained statistically significant after adjustment for multiple testing.

\section{Discussion}

We found that increased consumption of a number of individual diet items, including some but not all of the items expected to be high in arsenic concentrations, was associated with increasing toenail arsenic concentrations in this U.S. population. Importantly, although toenail arsenic increased with household water arsenic, we detected few interactions between household water arsenic and diet; this suggests that responses to dietary arsenic exposure were not highly sensitive to exposure via water.

\section{Grains, especially rice}

We expected to find an association between toenail arsenic and rice consumption because elevated concentrations of arsenic in rice are well documented, both in the U.S. [48-50] and in Southeast Asia [51-54]. Moreover, previous studies have found positive associations between rice consumption and arsenic concentrations in both urine [55-58] and toenails [6]. However, rice consumption was relatively low in this study population: the median study participant reported eating no brown rice and eating white rice just 1-3 times per month. By contrast, consumption rates were higher in studies relating rice consumption and urinary arsenic concentrations
[55-58], consistent with a per capita rice consumption in the United States of about 0.4 cup of cooked rice per day (derived from USDA commodity consumption data [59]), with some sub-populations consuming up to 2.2 cups per day [60]. Thus, consumption of rice grains in this study population was probably not sufficiently high to leave a signal in a long-term biomarker like toenail clippings. More work is needed to evaluate the association between rice consumption and long-term biomarkers like toenail clippings in a population that regularly consumes rice.

\section{Fish and seafood}

Many previous studies have found that fish have high total arsenic concentrations compared to other food items $[5,7]$ and that fish and seafood contribute a large part of human exposure to total arsenic [2,5-7,12,61]. However, the arsenic in these items is expected to be predominantly in organic forms that are excreted from the body without undergoing biotransformation, such as arsenobetaine and arsenocholine [9]. Thus, our finding of elevated toenail arsenic - which is primarily in inorganic forms [22] - in subjects who consumed more dark meat fish (tuna steak, mackerel, salmon, sardines, bluefish, or swordfish), but not more fish overall, is somewhat unexpected. We do not have data on arsenic speciation for the fish consumed by our study population, but speculate that the forms of arsenic in these types of fish may be qualitatively different from other types of seafood: that is, some of the organic arsenic in these fish might be biotransformed to inorganic forms within the body that then circulate through the bloodstream before being incorporated into nails. This speculation will need to be assessed in further work that includes detailed data on the species of arsenic found in an individual's diet as well as both urinary and toenail arsenic biomarkers.

Table 3 Diet items that were differentially associated with toenail arsenic depending on household water arsenic

\begin{tabular}{|c|c|c|c|c|c|c|c|c|c|c|c|}
\hline \multirow{3}{*}{ Category } & \multirow{3}{*}{ Food } & \multicolumn{5}{|c|}{ Tap water arsenic $<1 \mu \mathrm{g} / \mathrm{L}$} & \multicolumn{5}{|c|}{ Tap water arsenic $\geq 1 \mu \mathrm{g} / \mathrm{L}$} \\
\hline & & \multirow[t]{2}{*}{$\hat{\boldsymbol{\beta}} \pm \mathrm{SE}^{2}$} & \multirow[t]{2}{*}{$P$} & \multirow[t]{2}{*}{$\begin{array}{r}\text { partial } \\
\mathbf{R}^{2}\end{array}$} & \multicolumn{2}{|c|}{$\begin{array}{l}\text { \%Change from } 5^{\text {th }} \\
\text { to } 95^{\text {th }} \text { percentile } \\
\text { consumers }^{1}\end{array}$} & \multirow[t]{2}{*}{$\hat{\boldsymbol{\beta}} \pm \mathrm{SE}$} & \multirow[t]{2}{*}{$P$} & \multirow[t]{2}{*}{$\begin{array}{r}\text { partial } \\
R^{2}\end{array}$} & \multicolumn{2}{|c|}{$\begin{array}{c}\% \text { Change from } 5^{\text {th }} \\
\text { to } 95^{\text {th }} \text { percentile } \\
\text { consumers }^{1}\end{array}$} \\
\hline & & & & & Males & Females & & & & Males & Females \\
\hline Meats & Hot dogs (beef or pork) & $-0.457 \pm 0.192$ & 0.018 & $0.8 \%$ & -18.2 & -6.5 & $0.564 \pm 0.356$ & 0.115 & $1.1 \%$ & 34.7 & 10.5 \\
\hline Grains & $\begin{array}{l}\text { Cooked oatmeal or } \\
\text { cooked oat bran (1 cup) }\end{array}$ & $0.085 \pm 0.099$ & 0.394 & $0.8 \%$ & 1.4 & 2.6 & $0.539 \pm 0.178$ & 0.003 & $3.2 \%$ & 18.2 & 35.8 \\
\hline Vegetables & $\begin{array}{l}\text { Beans or lentils, baked, } \\
\text { dried, or soup ( } 1 / 2 \text { cup) }\end{array}$ & $0.194 \pm 0.201$ & 0.335 & $0.6 \%$ & 6.6 & 6.6 & $1.144 \pm 0.398$ & 0.005 & $2.6 \%$ & 30.0 & 30.0 \\
\hline Beverages & $\begin{array}{l}\text { Liquor, e.g., whiskey, gin, } \\
\text { vodka (1 drink or shot) }\end{array}$ & $0.080 \pm 0.034$ & 0.019 & $1.5 \%$ & 11.7 & 4.5 & $-0.119 \pm 0.078$ & 0.126 & $-0.3 \%$ & -16.3 & -6.9 \\
\hline
\end{tabular}

Legend: Model results for the diet items for which the associations with In-transformed toenail arsenic concentration, adjusted for tap water arsenic concentrations and potential confounders, depended on whether the household tap water arsenic concentration was above or below $1 \mu \mathrm{g} / \mathrm{L}$. Sample sizes ranged from $\mathrm{n}=627-$ 648 for tap water arsenic $<1 \mu \mathrm{g} / \mathrm{L}$ and $\mathrm{n}=194-195$ for tap water arsenic $\geq 1 \mu \mathrm{g} / \mathrm{L}$.

${ }^{1}$ These columns summarize the percent change in predicted toenail arsenic concentration from $5^{\text {th }}$ to $95^{\text {th }}$ percentile consumers for males and for females; gender is included since males and females consumed some diet items (e.g., beer, wine) differently. 
Negative associations with toenail arsenic were found for several foods that may be considered alternatives to fish: eggs; beef, calf, or pork liver; and hamburger in the population as a whole, and hot dogs in the group with drinking water arsenic $<1 \mu \mathrm{g} / \mathrm{L}$. MacIntosh et al. [6] suggested that individuals who tend to consume these types of foods tend not to eat as much seafood. Future analyses exploring dietary patterns of "fish eaters" and "non-fish eaters" in other populations may help to further elucidate those at highest risk of arsenic exposure via diet.

\section{Alcoholic beverages}

Our findings of increased toenail arsenic with increased consumption of beer and wine are consistent with previous modeling studies [12] as well as epidemiological studies with both toenail [6] and urinary [62-64] arsenic biomarkers. This study was not designed to address the mechanisms behind this finding, but we can speculate based on previous research that high arsenic content in these beverages and/or impairment of arsenic detoxification processes within the body may be responsible. For example, beer and wine may themselves be a source of dietary arsenic due to contamination of key ingredients such as hops, rice, and grapes $[3,38,65,66]$. Alternatively, the use of diatomaceous earth in filtering these beverages prior to consumption could be responsible for such an association [67]. Moreover, past or current alcohol consumption was associated with increased total urinary arsenic concentrations in a study of bladder cancer in Taiwan [62]. Additionally, among individuals exposed to varying levels of water arsenic contamination, consumers of one or more alcoholic beverages per week had significantly higher proportions of inorganic urinary arsenic species when compared to individuals who consumed no alcoholic beverages [63,64], suggesting that alcohol may impair the body's ability to metabolize inorganic arsenic. Unfortunately, we could not address the issue of alcohol effects on arsenic metabolism as nearly all toenail arsenic is in the inorganic form [22], and few data are available on arsenic speciation in these beverages. Nonetheless, our results confirm previous studies suggesting that alcoholic beverages should be taken into account when evaluating exposure to arsenic via diet [12].

\section{Fruits and vegetables}

Although we did not observe any associations with particular fruits or vegetables containing specific vitamins or micronutrients known to enhance arsenic detoxification $[41,45]$, we did find that several vegetables and one fruit were positively associated with water-corrected toenail arsenic, consistent with the modeling study of Xue et al. [12]. However, only the association with
Brussels sprouts remained statistically significant after correction for multiple testing. This finding is consistent with recent studies documenting high concentrations of arsenic in Brussels sprouts and other cruciferous vegetables [13] that may result from their high concentrations of sulfur; arsenite is known to bind preferentially to sulfur-containing compounds [68] as part of cellular detoxification of arsenic in plants [69]. As such, further evaluation of Brussels sprouts and other cruciferous plants containing high concentrations of sulfur [70] may be warranted, especially in geographic areas where soils or irrigation water may contain high concentrations of arsenic.

\section{Foods cooked in water}

In addition to Brussels sprouts, toenail arsenic was related to consumption of several other foods that are often - but not always - cooked in water, including oatmeal and legumes (beans or lentils). This was more evident for the sub-population with household water arsenic concentrations $\geq 1 \mu \mathrm{g} / \mathrm{L}$, although not statistically significant after correction for multiple comparisons. These relationships might reflect arsenic exposure from cooking water rather than from the uncooked foods themselves. However, we do not have information about the exact processes used in preparing these foods, and there were no associations for many other foods cooked in water (e.g., rice, pasta, potatoes, other vegetables). Thus, it is not clear whether it is the water or these foods themselves that are driving this association.

The EFSA report [2] noted that cooking foods in contaminated water could increase dietary arsenic exposure. Arsenic concentrations in cooking water, the type of food processing, time, temperature, and cooking medium can all affect arsenic concentrations in prepared final products. For example, arsenic concentrations in prepared rice [71-73] and vegetables [74] can be higher than in the raw foods when cooked in arsenic-contaminated water. However, cooking rice in excess water - even if the water itself is contaminated with arsenic - can reduce the arsenic concentrations in the prepared product [75]. Why Brussels sprouts, oatmeal and beans/lentils emerged from our analysis, but not other foods that are often cooked in water, such as rice, requires further scrutiny and replication in other study populations.

\section{Potential limitations}

There are some limitations to this study. First, as noted above, we do not have information about the species of arsenic - inorganic versus organic, or the kinds of organic arsenic - consumed by the study participants. Thus, although we can report associations between individual diet items and toenail arsenic, which reflects inorganic arsenic circulating in the body $[22,25]$, we 
cannot infer the potential toxicity of arsenic exposure via diet. Second, although toenails can have limitations as biomarkers due to variability in growth rate among individuals, the risk of external contamination, and inconsistent protocols for collection and analysis [23], we have minimized these problems in this study by comparing toenail samples to diet information over a 12 month time frame, collecting toenails immediately after bathing and sonicating them prior to analysis, and using standardized analytical procedures for all subjects [41]. Third, although we have matched the temporal scale of our dietary information to that represented by toenail clippings, food frequency questionnaires are less precise relative to other tools such as dietary records [76]. Because our data on consumption rates are likely to be less precise than our estimates of toenail arsenic concentration, we have violated the assumption that the predictor variables are known more precisely than the response variable. Fortunately, this violation tends to bias results towards the null [77], and so should not result in false positive findings. Finally, while we adjusted for case status, many of the participants were cancer cases. Although this could affect the generalizability of our findings since it is plausible that these individuals process arsenic differently than non-cancer cases [41], the associations with dark meat fish, white wine, beer and Brussels sprouts were also present in analyses only of control subjects (data not shown).

\section{Conclusions}

We found that arsenic concentrations in toenail clippings, a known biomarker of exposure [19,21,23], were correlated with individual diet items, particularly alcoholic beverages and Brussels sprouts, but also dark meat fish. Some foods cooked in water also were associated with higher toenail arsenic concentrations, especially among those with higher water arsenic concentrations, suggesting that exposure might be reduced by using alternative water sources in cooking or by using alternative cooking procedures. The fact that several diet items each accounted for $1-2 \%$ of the variability in log-transformed toenail arsenic even after correction for water exposure suggests that food is an exposure route likely to impact the population as a whole, regardless of drinking water arsenic concentrations. Further research is needed to identify patterns of dietary exposure that may pose particular risk, especially in populations expected to be vulnerable to exposure, such as pregnant women and infants [2].

\section{Additional file}

Additional file 1: Table S1. Conversions from FFQ responses to servings per day, assuming a 30-day month.
Competing interests

The authors declare no competing financial interests with this work.

\section{Authors' contributions}

KLC, RK, MRK, CLF and MSZ designed the research and conducted and interpreted analyses. KLC, RK and MRK drafted the manuscript. MRK conceived and designed the parent study, obtained funding, and collected data. JFG and TP provided interpretations of results. VS coordinated data collection and provided technical support, and JSM collected data. All authors critically revised the manuscript and have read and approved the manuscript.

\section{Acknowledgments}

This work was supported in part by grants P01 ES022832, P20 ES018175, P42 ES007373 and R01 CA57494 from the National Institute of Environmental Health Sciences (NIEHS), US National Institutes of Health (NIH); grant CA57494 from the National Cancer Institute (NCI), NIH; and RD-83544201 and RD-834599010 from the US Environmental Protection Agency (USEPA). The NIEHS was not involved in the design and conduct of the study or the collection, management, analysis, and interpretation of the data. Its contents are solely the responsibility of the authors and do not necessarily represent the official views of the NIEHS, NCI, NIH, or USEPA. Further, USEPA does not endorse the purchase of any commercial products or services mentioned in the publication. We thank Ángel A. Carbonell-Barrachina and Melissa Slotnick for their helpful comments during the review process. This manuscript advanced substantially while KLC was a Visiting Scholar at the W.K. Kellogg Biological Station.

\section{Author details}

${ }^{1}$ Department of Biological Sciences, Dartmouth College, Hanover, NH, USA. ${ }^{2}$ School of Marine and Atmospheric Sciences, Stony Brook University, Stony Brook, NY, USA. ${ }^{3}$ Department of Epidemiology, Gillings School of Global Public Health at the University of North Carolina, Chapel Hill, NC, USA. ${ }^{4}$ Section of Biostatistics and Epidemiology, Geisel School of Medicine at Dartmouth, Hanover, NH, USA.

Received: 12 July 2013 Accepted: 26 October 2013 Published: 16 November 2013

\section{References}

1. Kordas K, Lonnerdal B, Stoltzfuss RJ: Interactions between nutrition and environmental exposures: Effects on health outcomes in women and children. J Nutr 2007, 137:2794-2797.

2. European Food Safety Authority: EFSA Panel on Contaminants in the Food Chain (CONTAM): Scientific Opinion on Arsenic in Food. EFSA J 2009, 7:1351.

3. IARC Working Group on the Evaluation of Carcinogenic Risks to Humans: Some Drinking-Water Disinfectants and Contaminants, Including Arsenic. Lyon, France: World Health Organization International Agency for Research on Cancer; 2004.

4. Meliker JR, Franzblau A, Slotnick MJ, Nriagu JO: Major contributors to inorganic arsenic intake in southeastern Michigan. Int J Hyg Environ Health 2006, 209:399-411.

5. Tao SSH, Bolger PM: Dietary arsenic intakes in the United States: FDA total diet study, September 1991-December 1996. Food Addit Contam 1998, 16:465-472.

6. Maclntosh DL, Williams PL, Hunter DJ, Sampson LA, Morris SC, Willett WC, Rimm EB: Evaluation of a food frequency questionnaire food composition approach for estimating dietary intake of inorganic arsenic and methylmercury. Cancer Epidem Biomar 1997, 6:1043-1050.

7. Schoof RA, Yost LJ, Eickhoff J, Crecelius EA, Cragin DW, Meacher DM, Menzel DB: A market basket survey of inorganic arsenic in food. Food Chem Toxicol 1999, 37:839-846.

8. Dabeka RW, McKenzie AD, Lacroix GMA, Cleroux C, Bowe S, Graham RA, Conacher HBS, Verdier P: Survey of arsenic in total diet food composites and estimation of the dietary-intake of arsenic by Canadian adults and children. J AOAC Int 1993, 76:14-25.

9. Francesconi KA: Arsenic species in seafood: Origin and human health implications. Pure Appl Chem 2010, 82:373-381.

10. Meharg AA, Deacon C, Campbell RCJ, Carey AM, Williams PN, Feldmann J, Raab A: Inorganic arsenic levels in rice milk exceed EU and US drinking water standards. J Environ Monit 2008, 10:428-431. 
11. Meharg AA, Sun GX, Williams PN, Adomako E, Deacon C, Zhu YG, Feldmann J, Raab A: Inorganic arsenic levels in baby rice are of concern. Environ Pollut 2008, 152:746-749.

12. Xue JP, Zartarian V, Wang SW, Liu SV, Georgopoulos P: Probabilistic Modeling of Dietary Arsenic Exposure and Dose and Evaluation with 2003-2004 NHANES Data. Environ Health Persp 2010, 118:345-350.

13. Ramirez-Andreotta MD, Brusseau ML, Artiola JF, Maier RM: A greenhouse and field-based study to determine the accumulation of arsenic in common homegrown vegetables grown in mining-affected soils. Sci Tot Environ 2013, 443:299-306.

14. Navas-Acien A, Francesconi KA, Silbergeld EK, Guallar E: Seafood intake and urine concentrations of total arsenic, dimethylarsinate and arsenobetaine in the US population. Environ Res 2011, 111:110-118.

15. Georgopoulos PG, Wang SW, Yang YC, Xue JP, Zartarian VG, McCurdy T, Ozkaynak HK: Biologically based modeling of multimedia, multipathway, multiroute population exposures to arsenic. J Expo Sci Env Epid 2008, 18:462-476.

16. Meacher DM, Menzel DB, Dillencourt MD, Bic LF, Schoof RA, Yost $\sqcup$, Eickhoff JC, Farr CH: Estimation of multimedia inorganic arsenic intake in the US population. Hum Ecol Risk Assess 2002, 8:1697-1721.

17. Maclntosh DL, Spengler JD, Ozkaynak H, Tsai LH, Ryan PB: Dietary exposures to selected metals and pesticides. Environ Health Persp 1996, 104:202-209.

18. Yost $\sqcup$, Tao SH, Egan SK, Barraj LM, Smith KM, Tsuji JS, Lowney YW, Schoof RA, Rachman NJ: Estimation of dietary intake of inorganic arsenic in US children. Hum Ecol Risk Assess 2004, 10:473-483.

19. Karagas MR, Tosteson TD, Blum J, Klaue B, Weiss JE, Stannard V, Spate V, Morris JS: Measurement of low levels of arsenic exposure: A comparison of water and toenail concentrations. Am J Epidemol 2000, 152:84-90.

20. Wickre JB, Karagas MR, Folt CL, Sturup S: Environmental exposure and fingernail analysis of arsenic and mercury in children and adults in a Nicaraguan gold mining community. Arch Environ Health 2004, 59:400-409.

21. Slotnick MJ, Meliker JR, Nriagu JO: Intra-individual variability in toenail arsenic concentrations in a Michigan population, USA. J Expo Sci Env Epid 2008, 18:149-157.

22. Button M, Jenkin GRT, Harrington CF, Watts MJ: Human toenails as a biomarker of exposure to elevated environmental arsenic. J Environ Monitor 2009, 11:610-617.

23. Orloff K, Mistry K, Metcalf S: Biomonitoring for environmental exposures to arsenic. J Toxicol Env Health B 2009, 12:509-524

24. Button M: Toenails reveal exposure to environmental arsenic. Trends Anal Chem 2009, 28:III-IV.

25. Slotnick MJ, Nriagu JO: Validity of human nails as a biomarker of arsenic and selenium exposure: A review. Environ Res 2006, 102:125-139.

26. Mandal BK, Ogra Y, Suzuki KT: Speciation of arsenic in human nail and hair from arsenic-affected area by HPLC-inductively coupled argon plasma mass spectrometry. Toxicol Appl Pharmacol 2003, 189:73-83.

27. Hinwood AL, Sim MR, Jolley D, de Klerk N, Bastone EB, Gerostamoulos J, Drummer OH: Hair and toenail arsenic concentrations of residents living in areas with high environmental arsenic concentrations. Environ Health Persp 2003, 111:187-193.

28. Slotnick MJ, Meliker JR, AvRuskin GA, Ghosh D, Nriagu JO: Toenails as a biomarker of inorganic arsenic intake from drinking water and foods. J Toxicol Env Health A 2007, 70:148-158.

29. Karagas MR, Tosteson TD, Blum J, Morris JS, Baron JA, Klaue B: Design of an epidemiologic study of drinking water arsenic exposure and skin and bladder cancer risk in a US population. Environ Health Persp 1998, 106:1047-1050.

30. Fortuny J, Kogevinas M, Zens MS, Schned A, Andrew AS, Heaney J, Kelsey KT, Karagas MR: Analgesic and anti-inflammatory drug use and risk of bladder cancer: a population based case control study. BMC Urol 2007, 7:13. doi:10.1186/1471-2490-1187-1113.

31. Brinkman MT, Karagas MR, Zens MS, Schned A, Reulen RC, Zeegers MP: Minerals and vitamins and the risk of bladder cancer: results from the New Hampshire Study. Cancer Cause Control 2010, 21:609-619.

32. Applebaum KM, Karagas MR, Hunter DJ, Catalano PJ, Byler SH, Morris S, Nelson $\mathrm{HH}$ : Polymorphisms in nucleotide excision repair genes, arsenic exposure, and non-melanoma skin cancer in New Hampshire. Environ Health Persp 2007, 115:1231-1236.

33. Karagas MR, Stukel TA, Morris JS, Tosteson TD, Weiss JE, Spencer SK, Greenberg ER: Skin cancer risk in relation to toenail arsenic concentrations in a US population-based case-control study. Am J Epidemol 2001, 153:559-565.
34. Peters SC, Blum JD, Karagas MR, Chamberlain CP, Sjostrom DJ: Sources and exposure of the New Hampshire population to arsenic in public and private drinking water supplies. Chem Geol 2006, 228:72-84.

35. Peters SC, Blum JD, Klaue B, Karagas MR: Arsenic occurrence in New Hampshire drinking water. Environ Sci Technol 1999, 33:1328-1333.

36. Ayotte JD, Nolan BT, Nucklos JR, Cantor KP, Robinson GR, Baris D, Hayes L, Karagas M, Bress W, Silverman DT, Lubin JH: Modeling the probability of arsenic in groundwater in New England as a tool for exposure assessment. Environ Sci Technol 2006, 40:3578-3585.

37. Rees JR, Sturup S, Chen C, Folt C, Karagas MR: Toenail mercury and dietary fish consumption. J Expo Sci Env Epid 2007, 17:25-30.

38. Crecelius EA: Arsenite and arsenate levels in wine. B Environ Contam Tox 1977, 18:227-230

39. Willett WC, Sampson L, Stampfer MJ, Rosner B, Bain C, Witschi J, Hennekens CH, Speizer FE: Reproducibility and Validity of a Semiquantitative Food Frequency Questionnaire. Am J Epidemol 1985, 122:51-65.

40. Salvini S, Hunter DJ, Sampson L, Stampfer MJ, Colditz GA, Rosner B, Willett WC: Food-Based Validation of A Dietary Questionnaire - the Effects of Week-ToWeek Variation in Food-Consumption. Int J Epidemol 1989, 18:858-867.

41. Gruber JF, Karagas MR, Gilbert-Diamond D, Bagley PJ, Zens MS, Sayarath V, Punshon T, Morris JS, Cottingham KL: Association between toenail arsenic concentration and dietary factors in a New Hampshire population. Nutr J 2012, 11:45. doi:10.1186/1475-2891-1111-1145.

42. Willett W: Nutritional Epidemiology. 2nd edition. New York, NY: Oxford University Press; 1998.

43. Neter J, Kutner MH, Nachtsheim CJ, Wasserman W: Applied Linear Statistical Models. Chicago, IL: Richard D. Irwin, Inc.; 1996.

44. Lindberg AL, Ekstrom EC, Nermell B, Rahman M, Lonnerdal B, Persson LA Vahter M: Gender and age differences in the metabolism of inorganic arsenic in a highly exposed population in Bangladesh. Environ Res 2008, 106:110-120.

45. Tseng $\mathrm{CH}$ : A review on environmental factors regulating arsenic methylation in humans. Toxicol Appl Pharmacol 2009, 235:338-350.

46. Dabney AR, Storey JD: Q-value estimation for false discovery rate control $R$ package. [http://genomics.princeton.edu/storeylab/qvalue/index.html].

47. Storey JD: The positive false discovery rate: A Bayesian interpretation and the q-value. Ann Stat 2003, 31:2013-2035.

48. Nriagu JO, Lin TS: Trace-metals in wild rice sold in the United States. Sci Tot Environ 1995, 172:223-228.

49. Williams PN, Price AH, Raab A, Hossain SA, Feldmann J, Meharg AA: Variation in arsenic speciation and concentration in paddy rice related to dietary exposure. Environ Sci Technol 2005, 39:5531-5540.

50. Williams PN, Raab A, Feldmann J, Meharg AA: Market basket survey shows elevated levels of as in South Central U.S. processed rice compared to California: consequences for human dietary exposure. Environ Sci Technol 2007, 41:2178-2183.

51. Abedin MJ, Cotter-Howells J, Meharg AA: Arsenic uptake and accumulation in rice (Oryza sativa L.) irrigated with contaminated water. Plant Soil 2002, 240:311-319.

52. Meharg AA, Rahman M: Arsenic contamination of Bangladesh paddy field soils: Implications for rice contribution to arsenic consumption. Environ Sci Technol 2003, 37:229-234.

53. van Geen A, Zheng Y, Cheng Z, He Y, Dhar RK, Garnier JM, Rose J, Seddique A, Hoque MA, Ahmed KM: Impact of irrigating rice paddies with groundwater containing arsenic in Bangladesh. Sci Tot Environ 2006, 367:769-777.

54. Williams PN, Islam MR, Adomako EE, Raab A, Hossain SA, Zhu YG, Feldmann J, Meharg AA: Increase in rice grain arsenic for regions of bangladesh irrigating paddies with elevated arsenic in groundwaters. Environ Sci Technol 2006, 40:4903-4908.

55. Davis MA, Mackenzie TA, Cottingham KL, Gilbert-Diamond D, Punshon T, Karagas MR: Rice consumption and urinary arsenic concentrations in U.S. Children. Environ Health Perspect 2012, 120:1418-1424.

56. Cascio C, Raab A, Jenkins RO, Feldmann J, Meharg AA, Haris PI: The impact of a rice based diet on urinary arsenic. J Environ Monitor 2011, 13:257-265.

57. He Y, Zheng Y: Assessment of in vivo bioaccessibility of arsenic in dietary rice by a mass balance approach. Sci Tot Environ 2010, 408:1430-1436.

58. Gilbert-Diamond D, Cottingham KL, Gruber JF, Punshon T, Sayarath V, Gandolfi AJ, Baker ER, Jackson BP, Folt CL, Karagas MR: Rice consumption contributes to arsenic exposure in US women. Proc Nat Acad Sci USA 2011, 108:20656-20660. 
59. Commodity Consumption by Population Characteristics. [http://www.ers.usda. gov/datafiles/Commodity_Consumption_by_Population_Characteristics/ Food_Availability/fads_grain.xls].

60. Batres-Marquez SP, Jensen HH, Upton J: Rice consumption in the United States: recent evidence from food consumption surveys. J Am Diet Assoc 2009, 109:1719-1727.

61. Schoof RA, Yager JW: Variation of total and speciated arsenic in commonly consumed fish and seafood. Hum Ecol Risk Assess 2007, 13:946-965.

62. Huang YK, Huang YL, Hsueh YM, Yang MH, Wu MM, Chen SY, Hsu LI, Chen CJ: Arsenic exposure, urinary arsenic speciation, and the incidence of urothelial carcinoma: a twelve-year follow-up study. Cancer Cause Control 2008, 19:829-839.

63. Hopenhayn-Rich C, Biggs ML, Smith AH, Kalman DA, Moore LE: Methylation study of a population environmentally exposed to arsenic in drinking water. Environ Health Persp 1996, 104:620-628.

64. Hsueh YM, Ko YF, Huang YK, Chen HW, Chiou HY, Huang YL, Yang MH, Chen CJ: Determinants of inorganic arsenic methylation capability among residents of the Lanyang Basin, Taiwan: arsenic and selenium exposure and alcohol consumption. Toxicol Lett 2003, 137:49-63.

65. Donadini G, Spalla S, Beone GM: Arsenic, cadmium and lead in beers from the Italian market. J Inst Brewing 2008, 114:283-288.

66. Copping M: Death in the beer glass: the Manchester arsenic-in-beer epidemic of 1900-1 and the long-term poisoning of beer. J Brewery Hist Soc 2009, 132:31-57.

67. Beer filtration could add arsenic. [http://www.rsc.org/chemistryworld/2013/ 04/filter-kieselguhr-arsenic-beer].

68. Jackson BP, Taylor VF, Punshon T, Cottingham KL: Arsenic concentration and speciation in infant formulas and first foods. Pure Appl Chem 2012, 84:215-223.

69. Schmoger MEV, Oven M, Grill E: Detoxification of arsenic by phytochelatins in plants. Plant Physiol 2000, 122:793-801.

70. Stoewsand GS: Bioactive organosulfur phytochemicals in Brassica oleracea vegetables - a review. Food Chem Toxicol 1995, 33:537-543.

71. Laparra JM, Velez D, Barbera R, Farre R, Montoro R: Bioavailability of inorganic arsenic in cooked rice: Practical aspects for human health risk assessments. J Agricult Food Chem 2005, 53:8829-8833.

72. Torres-Escribano S, Leal M, Velez D, Montoro R: Total and inorganic arsenic concentrations in rice sold in Spain, effect of cooking, and risk assessments. Environ Sci Technol 2008, 42:3867-3872.

73. Ackerman AH, Creed PA, Parks AN, Fricke MW, Schwegel CA, Creed JT, Heitkemper DT, Vela NP: Comparison of a chemical and enzymatic extraction of arsenic from rice and an assessment of the arsenic absorption from contaminated water by cooked rice. Environ Sci Technol 2005, 39:5241-5246.

74. Diaz OP, Leyton I, Munoz O, Nunez N, Devesa V, Suner MA, Velez D, Montoro R: Contribution of water, bread, and vegetables (raw and cooked) to dietary intake of inorganic arsenic in a rural village of Northern Chile. J Agricult Food Chem 2004, 52:1773-1779.

75. Rahman MA, Hasegawa H, Rahman MM, Miah MAM: Influence of cooking method on arsenic retention in cooked rice related to dietary exposure. Sci Tot Environ 2006, 370:51-60.

76. Thompson FE, Subar AF: Dietary assessment methods. In Nutrition in the Prevention and Treatment of Disease. 2nd edition. Edited by Coulston AM, Boushey CJ. Boston, MA: Academic Press; 2008:39.

77. Draper NR, Smith H: Applied Regression Analysis. New York, NY: Wiley-Interscience; 1998.

\section{Submit your next manuscript to BioMed Central and take full advantage of:}

- Convenient online submission

- Thorough peer review

- No space constraints or color figure charges

- Immediate publication on acceptance

- Inclusion in PubMed, CAS, Scopus and Google Scholar

- Research which is freely available for redistribution

Submit your manuscript at www.biomedcentral.com/submit 